\title{
Strategi Pemasaran Produk Animasi PT Ayena Mandiri Sinema
}

\author{
Marketing Strategy of Animation Product in PT Ayena Mandiri Sinema
}

\author{
Aldrich Ilyas ${ }^{1^{*}}$, Sapta Raharja $a^{2 \sharp}$, dan Tjahja Muhandri ${ }^{3 *}$ \\ ${ }^{1}$ BPP Teknologi \\ Gd. Manajemen BPPT No. 720 lt. 2, Puspiptek, Tangerang Selatan \\ ${ }^{2}$ Departemen Teknologi Industri Pertanian, Fakultas Teknologi Pertanian Institut Pertanian Bogor \\ ${ }^{3}$ Departemen Ilmu dan Teknologi Pangan, Fakultas Teknologi Pertanian Institut Pertanian Bogor \\ * Jl. Kamper Kampus IPB Darmaga, Bogor 16680
}

\begin{abstract}
ABSTRAK
PT Ayena Mandiri Sinema (PT AMS) adalah salah satu tenant (UKM) yang dibina oleh Balai Inkubator Teknologi (BIT) BPPT, bergerak dibidang animasi dan multimedia. Permasalahan utama yang dihadapi adalah ketika melakukan pemasaran terhadap produk Intelectual Property (IP) animasi, berupa film animasi yang berjudul Super Neli. Di Indonesia pada umumnya, pemasaran produk IP animasi didominasi oleh perusahaan besar baik dari luar negeri maupun dalam negeri, selain itu juga terdapat mitra-mitra pemasaran yang cukup berpengaruh. Hal ini mengakibatkan PT AMS menjadi tidak mampu bersaing dengan perusahaan yang besar, sehingga diperlukan suatu strategi pemasaran yang mempertimbangkan aspek bauran pemasaran dan preferensi konsumen. Dalam kajian ini dilakukan identifikasi preferensi konsumen Business to Customer dengan model Kano didapatkan hasil yang didominasi oleh atribut one dimensional, sedangkan konsumen Business to Business didapatkan atribut must be dan one dimensional yang dominan. Sehingga menjadi peluang untuk menjaga dan meningkatkan kualitas produk untuk bersaing dalam bauran pemasaran. Sedangkan nilai matriks IFE dan EFE terhadap faktor lingkungan adalah 2,864 dan 2,424, menunjukkan bahwa PT AMS dalam posisi pertumbuhan/ stabil. Hasil analisis SWOT yang mempertimbangkan aspek bauran pemasaran (produk, harga, promosi dan tempat) berupa strategi-strategi yang dievaluasi dengan QSPM sehingga menghasilkan strategi prioritas yaitu memperluas jaringan pemasaran produk animasi dengan promosi dan penetrasi pasar melalui kerjasama dengan agency.
\end{abstract}

Kata kunci: bauran pemasaran, preferensi kosumen, model kano, SWOT, QSPM

\section{ABSTRACT}

PT Ayena Mandiri Sinema (PT AMS) is one of the tenants (SMEs) fostered by the Incubator Center of Technology (BIT) BPPT, engaged in animation and multimedia. The main problem is when marketing Intellectual Property (IP) product animation, such as animated film called Super Neli. Animation film. Generally in Indonesia, marketing product animation of IP dominated by large companies both foreign and domestic, and there are also marketing partners which are quite influential. This make PT AMS be unable to compete with large companies, therefore, it is required a marketing strategy that consider mix marketing aspect and consumer preferences. In this study, identification consumer preference Business to Customer using Kano model is done, the result is dominated by one dimensional attributes while consumer Business to Business obtained attribute must be and one-dimensional dominant. So it becomes an opportunity to maintain and improve product quality to compete in the marketing mix. While the IFE and EFE matrix values of the environmental factors are 2.864 and 2.424, indicating that PT AMS in a position of growth/stability. The result of SWOT analysis that considered mix marketing aspect (product, price, promotion and place) are strategies, then evaluated by QSPM resulting priority strategy which is expanding the marketing network products animation with promotion and market penetration through cooperation with the agency.

Kev words: marketing mix, consumer preferences, kano model, SWOT, QSPM

*) Korespondensi:

Gd. Manajemen BPPT No. 720 1t. 2, Puspiptek, Tangerang Selatan; email: aldrich.ilyas@yahoo.co.id 


\section{PENDAHULUAN}

UKM merupakan sektor perekonomian yang sangat diperhitungkan di Indonesia. Peran UKM tidak hanya sebagai penyedia lapangan pekerjaan yang besar, namun juga sebagai penyumbang Produk Domestik Bruto (PDB) yang sangat berarti. Data Kementerian Koperasi dan UKM menunjukkan pada tahun 2012, kontribusi PDB nasional tersusun dari UMKM sebesar 59,08 \% (Usaha Mikro: 35,81\%, Usaha Kecil: 9,68\%, Usaha Menengah: 13,59\%), sedangkan usaha besar $40,92 \%$. Ditinjau dari sisi jumlah, pelaku UMKM pada tahun 2012 mencapai 56.534 .592 unit. Selain kontribusi terhadap ekonomi Indonesia, UKM dipandang sebagai sektor yang handal dalam menghadapi terpaan krisis ekonomi. Hal ini terbukti ketika terjadi krisis ekonomi, UKM masih tetap eksis sementara usaha besar banyak yang gulung tikar. Oleh karena itu daya saing UKM perlu dijaga dan ditingkatkan dalam rangka pengembangan usahanya, dengan memanfaatkan inovasi dan teknologi dibidang penelitian dan pengembangan, pembuatan keputusan, pemasaran, produk dan akses permodalan (Wahyuni et al., 2013).

Teknologi informasi perlu dilakukan pada UKM, karena hal ini penting agar produk-produk yang dihasilkan UKM mampu bersaing dengan produk dari industri besar atau produk impor (Rahmana 2009). Selain itu menurut Tambunan (2004), keterbatasan pengetahuan dan keahlian sumber daya manusia (SDM), penguasaan teknologi, manajemen organisasi dan pangsa pasar merupakan salah satu penyebab utama rendahnya daya saing UKM dibandingkan dengan Usaha Besar (UB).

Salah satu langkah perbaikan untuk menjadikan UKM berdaya saing adalah dengan memberikan pendampingan kepada UKM oleh suatu lembaga inkubator teknologi dan bisnis. Inkubator bisnis salah satu alternatif mencetak wirausaha baru karena pembinaan terintegritas (Agustina, 2011). Lembaga inkubator yang ada di Indonesia adalah Balai Inkubator Teknologi (BIT).

PT Ayena Mandiri Sinema (PT AMS) adalah salah satu tenant (UKM) yang dibina oleh Balai Inkubator Teknologi (BIT) BPPT, bergerak dibidang animasi dan multimedia. Sejak terbentuk tahun 2001, sudah banyak tenant (UKM) yang dibina oleh BIT. Namun masih terdapat banyak kekurangan yang dimiliki BIT dalam membina tenant, salah satunya adalah ketika tenant sedang melakukan penetrasi pasar, masih ada tenant yang mengalami kegagalan. Kesulitan dalam penetrasi pasar dihadapi oleh tenant PT AMS adalah ketika melakukan pemasaran terhadap produk Intelectual Property (IP) animasi.

Di Indonesia pada umumnya, pemasaran produk IP animasi didominasi oleh perusahaan besar, ditandai dengan membanjirinya film animasi dari luar negeri, seperti film-film animasi dari Walt Disney, Universal Studio, DreamWorks Animation, Pixar Animation Studio, Warner Bros dan lain-lain. Selain itu juga hadirnya beberapa industri animasi dalam negeri yang bernaung di bawah stasiun televisi, seperti Tran7, MNC Animation, MD Animation, Emtek Group dan Dreamtoon serta production house lainnya. Hal ini mengakibatkan wirausaha pemula menjadi kalah bersaing dalam pemasaran (Karim dan Kristiana, 2014). Namun demikian, PT AMS yang merupakan industri kecil di bidang animasi yang berkembang melalui komunitas dan inkubator bisnis, tumbuh dan berkembang secara perlahanperlahan melalui pengembangan usaha animasi yang menghasilkan film animasi berseri dengan produk IP turunannya dan jasa pembuatan animasi yang dapat menopang perjalanan usahanya tersebut, sehingga diperlukan suatu strategi pemasaran yang mempertimbangkan aspek bauran pemasaran dan preferensi konsumen.

Tujuan penelitian ini adalah (1) mengidentifikasi atribut produk IP Animasi yang mempengaruhi preferensi konsumen, (2) mengidentifikasi faktor-faktor internal dan eksternal yang mempengaruhi pemasaran bisnis tenant PT Ayena Mandiri Sinema, (3) menyusun strategi pemasaran bisnis tenant CV Ayena Mandiri Sinema yang berbasiskan preferensi konsumen terhadap nilai atribut produk IP Animasi, sehingga produk yang dihasilkan tenant dapat diterima oleh mitra.

\section{METODE PENELITIAN}

Lokasi penelitian dilaksanakan pada tenant binaan BIT BPPT yang bernana PT Ayena Mandiri Sinema, berlokasi di Jalan Sadarmana no. 125, Kota Cimahi Jawa Barat.

Teknik pengumpulan data dalam penelitian ini meliputi data primer dan data sekunder. Data primer dikumpulkan langsung dari sumber informasi, yaitu dengan wawancara dan kuesioner (kajian pemasaran dan preferensi konsumen), sedangkan data sekunder berasal dari studi pustaka. Responden dalam penelitian 
ini terdiri dari 2 jenis, yaitu responden preferensi konsumen ( $B$ to $C$ dan $B$ to $B$ ) dan responden kajian pemasaran. Responden preferensi konsumen $B$ to $C$ adalah masyarakat umum yang menyukai animasi sedangkan $B$ to $B$ adalah profesional dan pakar dibidang teknik, bisnis dan pemasaran produk animasi. Responden kajian pemasaran adalah pemilik PT AMS dan pakar dibidang animasi, yaitu ketua Cimahi Creative Association (CCA) di Cimahi.

Metode analisis yang digunakan pada penelitian ini adalah dengan menggunakan analisis model Kano, analisis bauran pemasaran, analisis faktor internal dan eksternal, analisis matriks internal eksternal (IE), analisis Strenghts, Weaknesses, Opportunities and Threaths (SWOT) dan analisis Quantitative Strategic Planning Matrix (QSPM). Model Kano digunakan untuk mengidentifikasi preferensi konsumen terhadap atribut produk IP animasi. Analisis bauran pemasaran untuk mengetahui kondisi pemasaran perusahaan baik dari aspek produk, harga, promosi dan tempat/distribusi. Analisis faktor internal dan eksternal untuk mengetahui faktor-faktor internal perusahaan baik kekuatan dan kelemahan serta faktor-faktor eksternal perusahaan berkaitan peluang dan ancaman yang dianggap penting. Analisis matriks IE untuk mengetahui posisi produk IP animasi PT AMS dan mempermudah dalam pemilihan alternatif strategi. Analisis SWOT digunakan untuk menyusun dan perumusan alternatif strategi pemasaran produk IP animasi PT AMS berdasarkan faktor internal dan ekternal. Kemudian analisis QSPM untuk mengevaluasi strategi pemasaran produk IP animasi, berdasarkan pada faktor-faktor sukses kritis internal dan eksternal yang diketahui sebelumnya.

\section{HASIL DAN PEMBAHASAN}

PT Ayena Mandiri Sinema merupakan salah satu tenant inkubasi bergerak di bidang animasi yang dibina oleh BIT BPPT sejak tahun 2013. PT Ayena Mandiri Sinema didirikan oleh beberapa anak muda yang termotivasi menjadi seorang teknoprener. Perjuangannya bermula ketika pada tahun 2011 tergabung dalam suatu komunitas animasi, yaitu Cimahi Creative Association (CCA) di gedung BITC Baros Cimahi, untuk melatih keahlian mereka dalam membuat animasi serta menumbuhkan jiwa kewirausahaan. Pada tanggal 19-21 Juli 2011 Pemerintah Kota
Cimahi bekerjasama dengan BIT BPT menyelenggarakan Technopreneurship-camp dalam rangka menumbuhkembangkan wirausaha baru berbasis teknologi kreatif, dengan berhasil menyeleksi tenant yang bernama Ayena Creative Studio menjadi benih awal tumbuhnya perusahaan PT AMS.

Sejak tahun 2013, Ayena Creative Studio berubah namanya menjadi Ayena Mandiri Sinema (AMS) serta berusaha untuk memiliki tempat usaha sendiri dan memulai berbisnis secara mandiri, yang sebelumnya hanya bergabung dalam aktivitas bisnis di komunitas. Salah satu produk animasi yang dihasilkan oleh PT AMS adalah IP animasi dengan tokoh Super Neli. IP animasi ini berupa film animasi yang berdurasi selama lima menit. Dalam proses produksi secara umum pembuatan produk animasi terbagi menjadi tiga tahapan utama, diantaranya adalah pre-production, production dan post-production.

Segmentasi pasar PT AMS adalah $B$ to $B$ dan $B$ to $C$. Kegiatan usaha dengan segmentasi $B$ to $B$ yaitu meliputi: pengembangan dan penjualan IP berupa film animasi, games animasi, desain merchandise animasi, komik dan produk turunan dari IP tersebut. Kegiatan usaha dalam B to C adalah menyelenggarakan pelatihan desain animasi dan pembuatan cerita dalam bentuk storyboard.

Pemasaran yang dilakukan oleh PT AMS adalah dengan cara penawaran langsung kepada calon konsumen (stasiun $t v$, perusahaan penjualan produk animasi lainnya) dan melalui kerjasama dengan mitra usaha sebagai pihak ketiga antara PT AMS dengan calon konsumen. Sehingga PT AMS perlu mengetahui preferensi konsumen terhadap salah satu produk IP animasi yaitu film Super Neli.

\section{Preferensi Konsumen Terhadap Atribut Produk}

Dalam penyusunan kuesioner menggunakan sudut pandang model Kano sehingga dalam menyusun atribut-atribut pertanyaan pun tidak lepas dari bagaimana model Kano memandang setiap atribut spesifik produk atau layanan yang mempengaruhi persepsi kepuasan konsumen (Boger et al. 1993). Identifikasi penetapan atributatribut pertanyaan untuk kuesioner dilakukan dengan melakukan diskusi dengan pihak pemilik PT AMS dan pakar dibidang animasi, yaitu ketua CCA di kota Cimahi. Adapun produk yang dianalisa adalah produk film dengan IP animasi Super Neli. Atribut-atribut dari film tersebut untuk mengetahui preferensi konsumen adalah: 
Karakter tokoh super neli,

> Tampilan 3D animasi dan sinematografi,

$>$ Isi cerita, dan

$>$ Nilai pesan moral.

Data-data responden terdiri dari 2 jenis, yaitu $B$ to $C$ dan $B$ to $B$.

\section{Analisis Model Kano dengan segmentasi $B$ to $C$}

Data primer preferensi konsumen dengan segmentasi $B$ to $C$ dilakukan terhadap 59 responden, kemudian dilakukan pemetaan preferensi konsumen menggunakan Model Kano terhadap 4 (empat) atribut dalam film Super Neli, didapatkan kategori one dimensional yang dominan (Tabel 1). Atribut karakter tokoh super neli dan kandungan isi cerita film memiliki kategori one dimensional yang dominan, namun untuk atribut 3D animasi sinematografi dan pesan moral kategori kategori one dimensional tidak sepenuhnya dominan tetapi juga diikuti oleh kategori indifferent, dikarenakan tidak semua responden menjadikan atribut ini paling penting. Data preferensi konsumen $B$ to $C$ tersaji dalam Tabel 1 .

Selanjutnya untuk mengukur tingkat kepuasan konsumen, dilakukan pemetaan atau mengelompokkan tiap atribut ke dalam kuadran model kano (Gambar 1). Berdasarkan Kuadran Model Kano (Gambar 1), atribut karakter tokoh Super Neli dan kandungan isi cerita film Super Neli termasuk dalam kategori one dimensional (Sauerwein et al. 1996). Dengan analisis bahwa kepuasan konsumen akan meningkat tinggi apabila film Super Neli memiliki karakter yang sangat kuat, menonjol dan khas serta kandungan isi cerita yang menarik, kreatif dan penuh dengan dinamika. Kemudian untuk atribut 3D animasi sinematografi dan pesan moral termasuk dalam kategori indifferent. Menunjukan bahwa kepuasan konsumen akan tetap rendah walaupun dengan tampilan gerak 3D animasi halus dan sinematografi yang menarik serta terdapat nilai-nilai budi pekerti luhur yang disampaikan dalam film super neli.

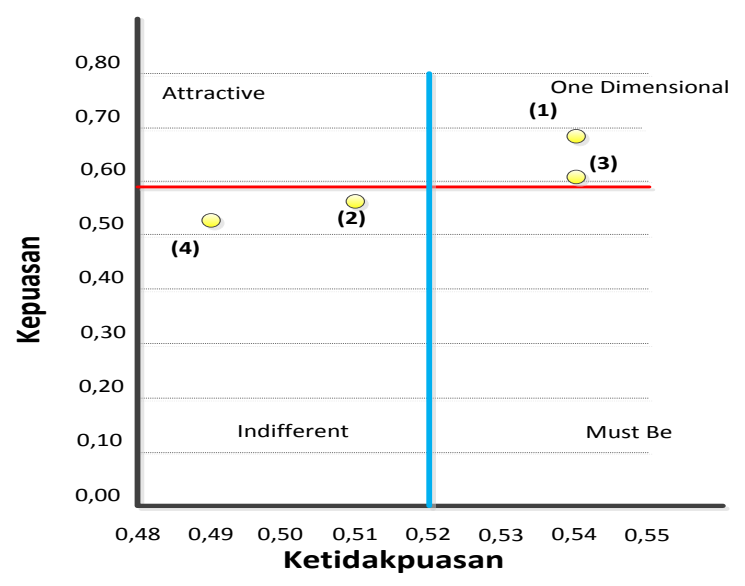

Gambar 1. Kuadran Kano film Super Neli dengan segmentasi $B$ to $C$

\section{Analisis Model Kano dengan Segmentasi $B$ to $B$}

Data primer preferensi konsumen dengan segmentasi $B$ to $B$ dilakukan terhadap 5 responden pakar dan profesional di bidang animasi dan multimedia, kemudian dilakukan pemetaan preferensi mitra bisnis menggunakan Model Kano terhadap 4 (empat) atribut dalam film Super Neli (Tabel 2). Atribut karakter tokoh super neli memiliki kategori must be yang dominan, 3D animasi dan sinematografi memiliki kategori must be dan one dimensional, isi cerita memiliki kategori must be dan pesan moral memiliki kategori one dimensional secara dominan. Data preferensi konsumen $B$ to $B$ tersaji dalam Tabel 2.

Selanjutnya untuk mengukur tingkat kepuasan konsumen, dilakukan pemetaan atau mengelompokkan tiap atribut ke dalam kuadran model kano. Dengan hasil atribut 3D animasi sinematografi dan pesan moral film Super Neli termasuk dalam kategori attractive dan one dimensional (Sauerwein et al. 1996). Dengan

Tabel 1. Rekapitulasi preferensi konsumen $B$ to $C$ Model Kano terhadap atribut produk

\begin{tabular}{|c|c|c|c|c|c|c|c|c|}
\hline \multirow{3}{*}{$\begin{array}{l}\text { Kategori model } \\
\text { kano }\end{array}$} & \multicolumn{8}{|c|}{ Atribut Produk IP Animasi (Film Super Neli) } \\
\hline & \multicolumn{2}{|c|}{ Karakter Tokoh } & \multicolumn{2}{|c|}{$\begin{array}{c}\text { 3D animasi dan } \\
\text { sinematografi }\end{array}$} & \multicolumn{2}{|c|}{ Isi Cerita } & \multicolumn{2}{|c|}{ Pesan Moral } \\
\hline & Jumlah & Persen & Jumlah & Persen & Jumlah & Persen & Jumlah & Persen \\
\hline Attractive & 11 & 18,6 & 8 & 13,5 & 9 & 15,2 & 7 & 11,8 \\
\hline Must Be & 3 & 5,1 & 5 & 8,5 & 6 & 10,2 & 5 & 8,5 \\
\hline One Dimensional & 27 & 45,8 & 24 & 40,7 & 25 & 42,4 & 23 & 39,0 \\
\hline Indifferent & 15 & 25,4 & 20 & 33,9 & 17 & 28,8 & 20 & 33,9 \\
\hline Questionable & 2 & 3,4 & 1 & 1,7 & 0 & 0 & 2 & 3,4 \\
\hline Reverse & 1 & 1,7 & 1 & 1,7 & 2 & 3,4 & 2 & 3,4 \\
\hline
\end{tabular}


Tabel 2. Rekapitulasi preferensi konsumen $B$ to $B$ Model Kano terhadap atribut produk

\begin{tabular}{|c|c|c|c|c|c|c|c|c|}
\hline \multirow{3}{*}{$\begin{array}{l}\text { Kategori model } \\
\text { kano }\end{array}$} & \multicolumn{8}{|c|}{ Atribut Produk IP Animasi (Film Super Neli) } \\
\hline & \multicolumn{2}{|c|}{ Karakter Tokoh } & \multicolumn{2}{|c|}{$\begin{array}{l}\text { 3D animasi dan } \\
\text { sinematografi }\end{array}$} & \multicolumn{2}{|c|}{ Isi Cerita } & \multicolumn{2}{|c|}{ Pesan Moral } \\
\hline & Jumlah & Persen & Jumlah & Persen & Jumlah & Persen & Jumlah & Persen \\
\hline Attractive & 0 & 0 & 1 & 20 & 1 & 20 & 0 & 0 \\
\hline Must Be & 3 & 60 & 2 & 40 & 2 & 40 & 1 & 20 \\
\hline One Dimensional & 2 & 40 & 2 & 40 & 1 & 20 & 3 & 60 \\
\hline Indifferent & 0 & 0 & 0 & 0 & 1 & 20 & 1 & 20 \\
\hline Questionable & 0 & 0 & 0 & 0 & 0 & 0 & 0 & 0 \\
\hline Reverse & 0 & 0 & 0 & 0 & 0 & 0 & 0 & 0 \\
\hline
\end{tabular}

analisis bahwa kepuasan konsumen akan meningkat tinggi karena tampilan 3D animasi dan sinematografi yang baik serta terdapat nilainilai budi pekerti luhur dalam film super neli. Kemudian untuk atribut karakter tokoh termasuk dalam kategori must be, menunjukan bahwa kepuasan konsumen akan tetap rendah apabila memiliki karakter tokoh animasi yang kuat, namun bila lemah maka ketidakpuasan akan tinggi. Atribut kandungan isi cerita termasuk dalam kategori indifferent, dengan analisis bahwa kepuasan konsumen akan tetap rendah walaupun isi cerita film menarik ataupun tidak. Kudran model Kano $B$ to $B$ tersaji dalam Gambar 2.

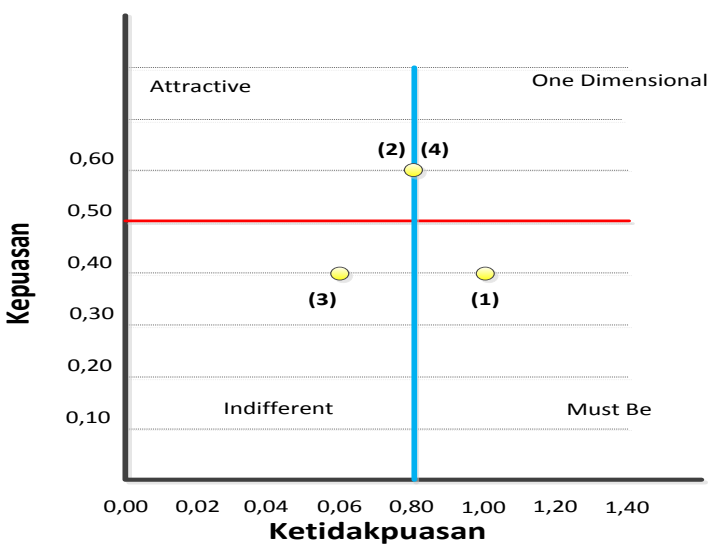

Gambar 2. Kuadran Kano film Super Neli dengan segmentasi $B$ to $B$

\section{Identifikasi Bauran Pemasaran Produk Animasi}

\section{Produk}

Produk animasi yang dihasilkan oleh PT AMS adalah IP animasi dan jasa pembuatan animasi. Jasa pembuatan animasi merupakan kegiatan produksi rutin yang dilakukan PT AMS, dikarenakan permintaannya secara berkala. Namun prospek bisnis produk IP animasi lebih baik, hal ini dikarenakan IP animasi memiliki diversifikasi produk dan prospek penjualan dapat lebih luas dan dalam rentang waktu yang lebih lama. Berdasarkan klasifikasi produk menurut Tjiptono (2008), produk yang dihasilkan PT AMS adalah unsought goods dan capital items, karena produk animasi pada umumnya konsumen terpikir untuk membelinya hanya sebagai produk pelengkap dan membantu salah satunya dalam promosi produk utama. Hasil dari analisis model Kano atribut IP animasi Super Neli Memiliki atribut one dimensional dan must be.

\section{Harga}

Penentuan harga produk IP animasi dan jasa pembuatan animasi yang dilakukan PT AMS adalah dengan cara negosiasi antara penjual dan pembeli (Kotler 1995). Parameter penetapan harga produk berdasarkan aspek biaya produksi, kualitas animasi dan tingkat kesulitan, serta harga pasar dan pesaing. Sehingga dalam penetapan harga produk animasi termasuk kedalam kategori demandbackward pricing (Tjiptono 2008).

\section{Promosi}

Strategi promosi yang dilakukan oleh PT AMS adalah melakukan promosi penjualan, public relations, personal selling dan direct marketing. Bentuk kegiatan promosi penjualan adalah pameran di dalam maupun di luar negeri, demoreel produk animasi dan kontes. Kegiatan public relations melalui pelatihan dan membentuk komunitas animasi. Strategi personal selling adalah menjaring konsumen melalui penawaran dan pengenalan produk yang diperoleh dari mulut ke mulut baik melalui penjual atau konsumen yang ada (Kusuma et al., 2013). Bentuk kegiatannya melalui presentasi dan pertemuan bisnis serta jaringan mitra dan agency. Strategi Kemudian kegiatan direct marketing melalui website internet dan pertemuan langung di studio animasi. 


\section{Tempat dan Distribusi}

Lokasi tempat penjualan melalui website internet, studio animasi, komunitas, tempat pelaksanaan pameran dan tempat lain yang memungkinkan. Sedangkan jaringan distribusi melalui mitra bisnis, jaringan komunitas, jaringan agency, jaringan sesama studio, jaringan personil dan lain sebagainya. Segmentasi wilayah penjualan di dalam negeri meliputi kota: Jabodetabek, Bandung, Cimahi dan Yogyakarta. Segmentasi wilayah luar negeri meliputi: Benua Amerika, Eropa, Australia dan Asia. Pemilihan sistem distribusi produk dengan sistem jual putus, didasarkan pada kemudahan pihak produsen dalam mengatur keuangan dan perputaran uang dalam operasional bisnis perusahaan (Jannah et al. 2013).

\section{Perumusan Strategi Pemasaran Produk Animasi}

\section{Identifikasi Matriks IFE dan Matriks EFE}

Melalui kuesioner yang telah diisi oleh pemilik dan manajemen perusahaan PT AMS serta ahli pakar di bidang animasi oleh ketua CCA, kemudian dilakukan pembobotan dengan menggunakan metode paried comparison dan pemberian peringkat (rating), sehingga dihasilkan matriks IFE pada Tabel 3, dengan parameter yaitu manajemen, produk dan teknologi, serta keuangan (David, 2009). Sedangkan matriks EFE pada Tabel 4, dengan aspek sosial budaya, ekonomi, konsumen, politik dan hukum, kemitraan dan pesaing (David, 2009).

Dari hasil evaluasi dan analisis yang telah dilakukan, selanjutnya dilakukan analisis internal eksternal yang menghasilkan matriks Internal-Eksternal (IE), dengan hasil posisi perusahaan pada kuadran kelima, yang berarti inti strategi yang diterapkan perusahaan adalah Strategi Pertumbuhan/Stabilitas (Gambar 3). Strategi yang disarankan adalah strategi penetrasi pasar, pengembangan produk dan pengembangan pasar serta meminimalkan biaya dan operasional yang tidak efisien untuk mengontrol mutu dan distribusi produk (Iskandar et al. 2013). Strategi penetrasi pasar yang dilakukan oleh perusahaan adalah menjalin kerjasama dengan agensi-agensi pemasaran produk animasi untuk mempermudah pemasaran. Strategi pengembangan produk yang dilakukan adalah membuat produk turunan IP animasi yang sesuai dengan keinginan konsumen. Strategi pengembangan pasar adalah menambah jaringan pemasaran di dalam dan di luar negeri, melalui jaringan agency maupun secara langsung.

\section{Analisis Matriks SWOT}

Setelah mengetahui posisi perusahaan saat ini dan diperoleh inti strategi perusahaan, maka selanjutnya adalah menyusun faktorfaktor strategi bagi perusahaan dengan menggunakan matriks SWOT. Hasil perumusan dikelompokan menjadi empat kelompok perumusan strategi yang terdiri dari strategi Kekuatan-Peluang (S-O), strategi KekuatanAncaman (S-T), strategi Kele-mahan-Peluang (W-O), dan strategi Kelemahan-Ancaman (W-T), seperti disajikan dalam Gambar 4.

Tabel 3. Perhitungan matriks IFE PT AMS

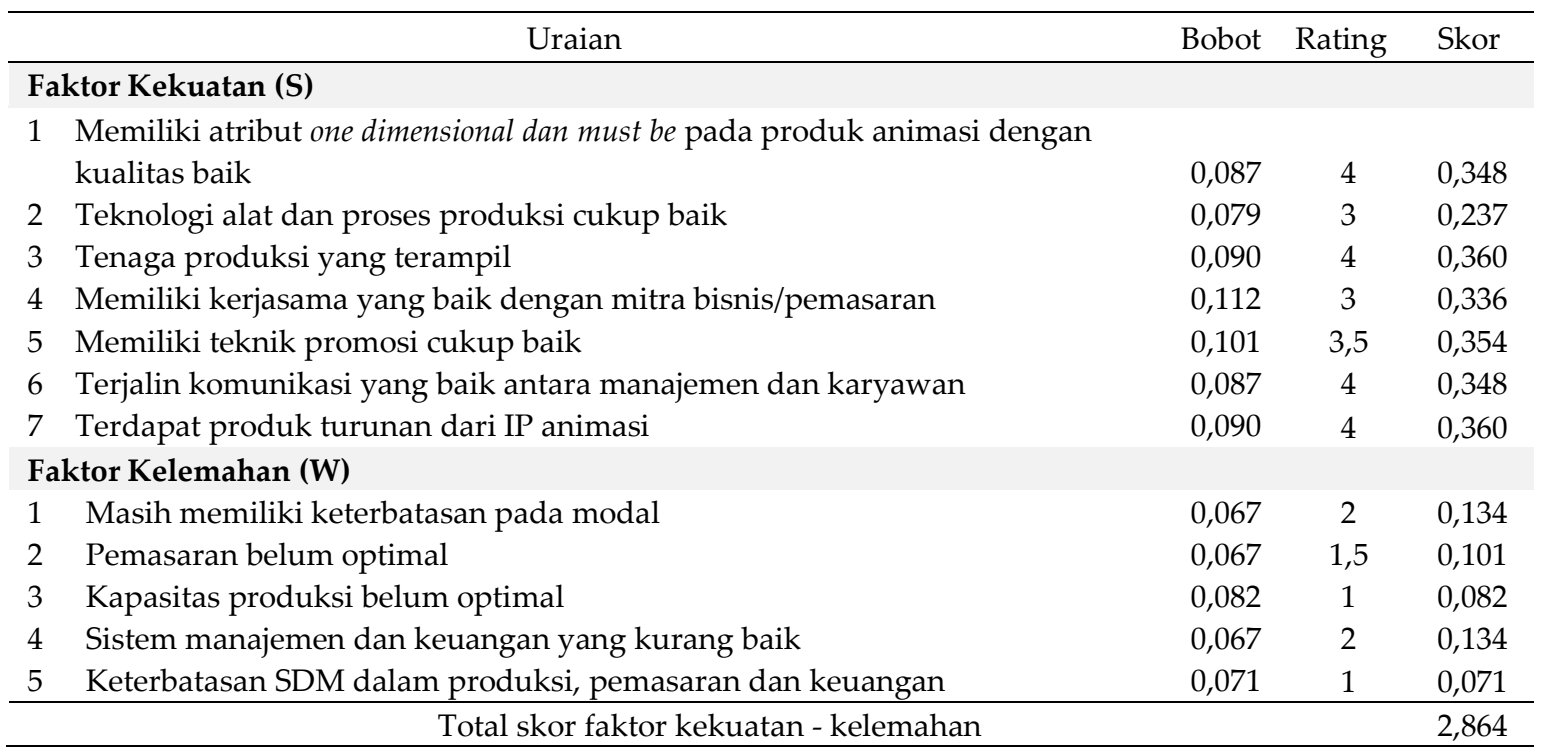


Tabel 4. Perhitungan matriks EFE PT AMS

\begin{tabular}{lccc}
\hline \multicolumn{1}{c}{ Uraian } & Bobot & Rating & Skor \\
\hline Faktor Peluang (O) & & \\
$1 \quad$ Permintaan pasar cukup besar & 0,144 & 3 & 0,432 \\
$2 \quad$ Cepat berkembangnya teknologi animasi & 0,089 & 3 & 0,267 \\
$3 \quad$ Meningkatnya kebutuhan masyarakat akan animasi & 0,128 & 3 & 0,384 \\
$4 \quad$ Dukungan pemerintah dan swasta dalam berkembangnya industri kreatif & 0,106 & 3,5 & 0,371 \\
$5 \quad$ Tumbuhnya komunitas-komunitas animasi & 0,089 & 4 & 0,356 \\
Faktor Ancaman (T) & 0,083 & 1,5 & 0,125 \\
$1 \quad$ Keberadaan perusahaan lain yang sejenis & 0,100 & 1,5 & 0,150 \\
$2 \quad$ Kurangnya daya dukung regulasi perizinan Pemerintah Daerah (Pemda) & 0,078 & 2 & 0,156 \\
$3 \quad$ Pemasaran didominasi perusahaan besar baik dalam negri atau luar negri & 0,105 & 1 & 0,105 \\
$4 \quad$ Jaringan penjualan produk animasi didominasi melalui media agency & 0,078 & 1 & 0,078 \\
$5 \quad$ Sulitnya mencari sumber pembiayaan & & 2,424 \\
\hline & Total skor faktor kekuatan - kelemahan &
\end{tabular}

\begin{tabular}{|c|c|c|c|c|c|}
\hline \multirow{9}{*}{ 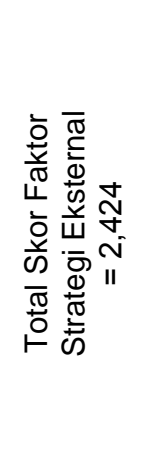 } & & \multirow[b]{3}{*}{4,0} & \multicolumn{3}{|c|}{ Total Skor Faktor Strategi Intenal = 2,864 } \\
\hline & & & Kuat & Sedang & Lemah \\
\hline & & & 3,0 & 2,0 & 1,0 \\
\hline & Tingai & \multirow[b]{2}{*}{3,0} & I & II & III \\
\hline & ו & & GROWTH & GROWTH & RETRENCHMENT \\
\hline & Sedana & \multirow[b]{2}{*}{2,0} & IV & V & VI \\
\hline & \multirow{3}{*}{ Rendah } & & STABILITY & GROWTISTABILITY & RETRENCHMENT \\
\hline & & \multirow{2}{*}{1,0} & VII & VIII & IX \\
\hline & & & GROWTH & GROWTH & RETRENCHMENT \\
\hline
\end{tabular}

Gambar 3. Matriks Internal-Eksternal (IE Matriks) PT AMS

Hasil dari perumusan alternatif-alternatif strategi pemasaran produk IP animasi PT AMS yang diperoleh melalui analisis matriks SWOT. Hasil matriks ini dianalisis dengan matriks QSP terhadap pilihan strategi yang muncul berdasarkan faktor-faktor kritis internal dan eksternal perusahaan. Evaluasi pemilihan strategi dilakukan dengan memberikan bobot pada setiap faktor kritis internal dan ekternal dan dipadukan/dikali dengan skor daya tarik alternatif strategi terhadap faktor kritis.

\section{Analisis Matriks QSP}

Evaluasi strategi pemasaran produk IP animasi untuk memutuskan strategi yang prioritas untuk diterapkan oleh PT AMS dengan menggunakan matriks QSP. Kemudian hasil evaluasi alternatif strategi tersebut diberi peringkat urutan prioritas strategi yang terbaik berdasarkan kondisi usaha PT AMS, hasil analisis dengan matriks QSP ini diurutkan berdasarkan prioritasnya seperti disajikan pada Tabel 5 .

Berdasarkan hasil perhitungan dalam matriks QSP, diperoleh strategi yang paling tepat diimplementasikan adalah memperluas jaringan pemasaran produk animasi dengan promosi dan penetrasi pasar melalui kerjasama dengan agency, memiliki total nilai daya tarik tertinggi di antara alternatif-alternatif strategi lainnya yaitu sebesar 6,196. Strategi-strategi prioritas tersebut agar mudah diimplemetasikan oleh PT AMS, maka perlu dikelompokan berdasarkan peran masingmasing strategi terhadap perusahaan.

\section{Implementasi strategi}

Dalam penelitian ini didapatkan lima pengelompokan implementasi strategi, yaitu:

\section{Pemasaran}

Memperluas jaringan pemasaran produk animasi dengan promosi dan penetrasi pasar melalui kerjasama dengan agency. Bentuk kegiatan promosi yang akan dilakukan adalah mengikuti pameran, promosi melalui jaringan kemitraan dengan komunitas, lembaga pemerintah dan swasta, serta agency pemasaran. Strategi penetrasi pasar yang harus dilakukan oleh perusahaan adalah melakukan kerjasama dengan agency pemasaran produk animasi untuk mempermudah pemasaran produk IP animasi. 


\begin{tabular}{|c|c|c|}
\hline \multirow{2}{*}{ Faktor Internal } & Faktor Kekuatan (S) & Faktor Kelemahan (W) \\
\hline & $\begin{array}{l}\text { 1. Memiliki atribut one dimensional } \\
\text { dan must be pada produk animasi } \\
\text { dengan kualitas baik, } \\
\text { 2. Teknologi alat dan proses } \\
\text { produksi cukup baik, } \\
\text { 3. Tenaga produksi yang terampil, } \\
\text { 4. Memiliki kerjasama yang baik } \\
\text { dengan mitra bisnis/ } \\
\text { pemasaran, } \\
\text { 5. Memiliki teknik promosi cukup } \\
\text { baik, } \\
\text { 6. Terjalin komunikasi yang baik } \\
\text { antara manajemen dan karyawan, } \\
\text { 7. Terdapat produk turunan dari IP } \\
\text { animasi. }\end{array}$ & $\begin{array}{l}\text { 1. Masih memiliki keterbatasan modal, } \\
\text { 2. Pemasaran belum optimal, } \\
\text { 3. Kapasitas produksi belum optimal, } \\
\text { 4. Sistem manajemen dan keuangan yang } \\
\text { kurang baik, } \\
\text { 5. Keterbatasan SDM dalam produksi, } \\
\text { pemasaran dan keuangan. }\end{array}$ \\
\hline Faktor Peluang (O) & Strategi SO & Strategi WO \\
\hline $\begin{array}{l}\text { 1. Permintaan pasar cukup } \\
\text { besar, } \\
\text { 2. Cepat berkembangnya } \\
\text { teknologi animasi, } \\
\text { 3. Meningkatnya kebutuhan } \\
\text { masyarakat akan animasi, } \\
\text { 4. Dukungan pemerintah dan } \\
\text { swasta dalam } \\
\text { berkembangnya industri } \\
\text { kreatif, } \\
\text { 5. Tumbuhnya komunitas - } \\
\text { komunitas animasi. }\end{array}$ & $\begin{array}{l}\text { 1. Meningkatkan kualitas dan } \\
\text { kuantitas atribut produk one } \\
\text { dimensional dengan teknologi dan } \\
\text { tenaga kerja yang terampil untuk } \\
\text { dapat bersaing dan } \\
\text { mengakomodir kebutuhan pasar } \\
\text { (S1, S2, S3, S6, S7, O1, O3). } \\
\text { 2. Memperluas jaringan pemasaran } \\
\text { produk animasi dengan promosi } \\
\text { dan penetrasi pasar melalui } \\
\text { kerjasama dengan agency (S4, S5, } \\
\text { S6, O1, O3). } \\
\text { 3. Mengembangkan diversifikasi } \\
\text { produk turunan dari IP animasi, } \\
\text { sesuai dengan kebutuhan } \\
\text { permintaan pasar (S2, S3, S7, O1, } \\
\text { O3). }\end{array}$ & $\begin{array}{l}\text { 1. Menjalin kerjasama dengan } \\
\text { pemerintah dan swasta dalam akses } \\
\text { modal, jaringan pemasaran dan } \\
\text { pelatihan capacity building (W1, W2, } \\
\text { W4, O4). } \\
\text { 2. Menjalin kerjasama dengan komunitas } \\
\text { dan studio animasi lainnya dalam } \\
\text { produksi, untuk menutupi kurangnya } \\
\text { kapasitas produksi dalam memenuhi } \\
\text { permintaan pasar (W3, O1, O3, O5). } \\
\text { 3. Mengadakan pelatihan kepada pelajar, } \\
\text { komunitas dan masyarakat untuk } \\
\text { menjaring SDM dalam meningkatkan } \\
\text { kapasitas produksi (W3, W5, O3, O5). } \\
\text { 4. Melatih karyawan baik secara } \\
\text { pemasaran, teknik dan manajemen, } \\
\text { sehingga dapat menutupi keterbatasan } \\
\text { kualitas dan kuantitas SDM dalam } \\
\text { produksi dan pemasaran (W2, W3, } \\
\text { W5, O1). }\end{array}$ \\
\hline Faktor Ancaman (T) & Strategi ST & Strategi WT \\
\hline $\begin{array}{l}\text { 1. Keberadaan perusahaan lain } \\
\text { yang sejenis, } \\
\text { 2. Kurangnya daya dukungan } \\
\text { regulasi perizinan Pemda, } \\
\text { 3. Pemasaran didominasi oleh } \\
\text { perusahaan besar baik dalam } \\
\text { negri atau luar negri, } \\
\text { 4. Jaringan penjualan produk } \\
\text { animasi didominasi melalui } \\
\text { media agency, } \\
\text { 5. Sulitnya mencari sumber } \\
\text { pembiayaan }\end{array}$ & $\begin{array}{l}\text { Melakukan kerjasama dengan } \\
\text { Pemda dan mitra swasta dalam } \\
\text { mempermudah proses perijinan (S4, } \\
\text { T2) }\end{array}$ & $\begin{array}{l}\text { 1. Memperbaiki sistem manajemen, } \\
\text { diberbagai bidang (W4, W5, O4, O5). } \\
\text { 2. Meningkatkan kerjasama dengan } \\
\text { investor/stakeholder terkait, baik } \\
\text { pemerintah dan swasta untuk } \\
\text { mendapatkan sumber permodalan } \\
\text { (skim permodalan) (W1, W3, T5). }\end{array}$ \\
\hline
\end{tabular}


Tabel 5. Urutan prioritas strategi dari matriks QSP PT AMS

\begin{tabular}{|c|c|c|c|}
\hline No & Alternatif Strategi & $\begin{array}{l}\text { Total Nilai } \\
\text { Daya Tarik }\end{array}$ & $\begin{array}{c}\text { Urutan } \\
\text { Prioritas }\end{array}$ \\
\hline 1. & $\begin{array}{l}\text { Meningkatkan kualitas dan kuantitas atribut produk one dimensional dengan } \\
\text { teknologi dan tenaga kerja yang terampil untuk dapat bersaing dan } \\
\text { mengakomodir kebutuhan pasar }\end{array}$ & 6,076 & 2 \\
\hline 2. & $\begin{array}{l}\text { Memperluas jaringan pemasaran produk animasi dengan promosi dan penetrasi } \\
\text { pasar melalui kerjasama dengan agency }\end{array}$ & 6,196 & 1 \\
\hline 3. & $\begin{array}{l}\text { Mengembangkan diversifikasi produk turunan dari IP animasi, sesuai dengan } \\
\text { kebutuhan permintaan pasar }\end{array}$ & 5,660 & 4 \\
\hline 4. & $\begin{array}{l}\text { Menjalin kerjasama dengan pemerintah dan swasta dalam akses modal, jaringan } \\
\text { pemasaran dan pelatihan capacity building }\end{array}$ & 6,024 & 3 \\
\hline 5. & $\begin{array}{l}\text { Menjalin kerjasama dengan komunitas dan studio animasi lainnya dalam } \\
\text { produksi, untuk menutupi kurangnya kapasitas produksi dalam memenuhi } \\
\text { permintaan pasar }\end{array}$ & 5,459 & 6 \\
\hline 6. & $\begin{array}{l}\text { Mengadakan pelatihan kepada pelajar, komunitas dan masyarakat untuk } \\
\text { menjaring SDM dalam meningkatkan kapasitas produksi }\end{array}$ & 4,902 & 8 \\
\hline 7 & $\begin{array}{l}\text { Melatih karyawan baik secara pemasaran, teknik dan manajemen, sehingga dapat } \\
\text { menutupi keterbatasan kualitas dan kuantitas SDM dalam produksi dan } \\
\text { pemasaran }\end{array}$ & 4,846 & 9 \\
\hline 8. & $\begin{array}{l}\text { Melakukan kerjasama dengan Pemda dan mitra swasta dalam mempermudah } \\
\text { proses perijinan }\end{array}$ & 4,956 & 7 \\
\hline 9. & Memperbaiki sistem manajemen diberbagai bidang & 4,604 & 10 \\
\hline 10. & $\begin{array}{l}\text { Meningkatkan kerjasama dengan investor/stakeholder terkait, baik pemerintah } \\
\text { dan swasta untuk mendapatkan sumber permodalan (skim permodalan) }\end{array}$ & 5,542 & 5 \\
\hline
\end{tabular}

Melatih karyawan baik secara pemasaran, teknik dan manajemen, sehingga dapat menutupi keterbatasan kualitas dan kuantitas SDM dalam produksi dan pemasaran. Melibatkan setiap karyawan yang berada dibidang pemasaran untuk mengikuti pelatihan pemasaran, kegiatan temu bisnis dengan mitra dan kegiatan promosi dengan mitra.

\section{Produksi}

Meningkatkan kualitas dan kuantitas atribut produk one dimensional dengan teknologi dan tenaga kerja yang terampil untuk dapat bersaing dan mengakomodir kebutuhan pasar. Meningkatkan kualitas dan kuantitas produk, dengan cara menggunakan peralatan software dan hardware dengan teknologi yang baik serta karyawan yang ada harus dilatih keterampilan dan keahliannya, sehingga dapat mengembangkan diversifikasi produk turunan dari IP animasi, sesuai dengan permintaan pasar. Menjalin kerjasama dengan komunitas dan studio animasi lainnya dan mengadakan pelatihan kepada pelajar, komunitas dan masyarakat untuk menjaring SDM dalam meningkatkan kapasitas produksi.

\section{Pemodalan}

Menjalin kerjasama dengan pemerintah dan swasta dalam akses modal serta meningkatkan kerjasama dengan investor/stakeholder terkait, jaringan pemasaran dan pelatihan capacity building. PT AMS perlu bekerjsama dengan lembaga pemerintah dan swasta yang memiliki akses permodalan dengan lembaga permodalan dan program pemberdayaan kewirausahaan serta sumber permodalan (skim permodalan).

\section{Manajemen}

Memperbaiki sistem manajemen diberbagai bidang. Sistem manajemen adalah meliputi proses perencanaan, pengorganisasian dan pengendalian. Salah satu keterbatasan yang dimiliki oleh PT AMS adalah kurang baiknya pengorganisasian dan pengelola SDM yang dikarenakan jumlahnya yang terbatas dan pengendalian dokumen perusahaan serta laporan keuangan perusahaan belum tertata dengan baik, sehingga perlu memperbaiki sistem manajemen pengorganisasian dan pengelola SDM, pengendalian dokumen perusahaan, serta laporan keuangan perusahaan.

\section{Legalitas}

Melakukan kerjasama dengan Pemda dan mitra swasta dalam mempermudah proses perijinan. Ayena Mandiri Sinema sejak tahun 2013 berusaha untuk mendaftarkan menjadi badan usaha. Kemudian pada bulan februari 2015 mendapatkan akte notaris pendirian badan usaha, namun legalitas ijin mendirikan badan usaha belum didapatkan, sehingga perlu dilakukan 
kerjasama dengan Pemda untuk lebih dipermudah dalam pengurusan ijin mendirikan usaha.

\section{KESIMPULAN}

Hasil analisis preferensi konsumen $B$ to $C$ terhadap atribut produk IP animasi Super Neli PT AMS adalah one dimensional yang dominan, sedangkan preferensi konsumen $B$ to $B$ adalah one dimensional dan must be. Sehingga kualitas produk IP Super Neli merupakan produk yang dapat bersaing.

Pemasaran produk IP animasi PT AMS dipengaruhi oleh faktor eksternal dan internal perusahaan. Aspek eksternal yaitu permintaan pasar; cepat berkembangnya teknologi animasi; dukungan pemerintah dan swasta; persaingan industri animasi; serta skema pembiayaan UKM. Sedangkan faktor internal perusahaan adalah atribut produk IP Super Neli termasuk dalam kategori one dimensional serta must be dan memiliki diversifikasi produk; memiliki tenaga kerja yang terampil dan teknik promosi serta pemasaran yang cukup, namun belum optimal dalam pemasaran dan kapasitas produksi; dan keterbatasan dalam SDM serta permodalan. Sehingga strategi prioritas untuk pemasaran produk IP Super Neli adalah memperluas jaringan pemasaran produk animasi dengan promosi dan penetrasi pasar melalui kerjasama dengan agency.

\section{DAFTAR PUSTAKA}

Agustina TS. 2011. Peran Inkubator Bisnis Perguruan Tinggi Dalam Meminimalkan Resiko Kegagalan Bagi Wirausaha Baru Pada Tahapan Awal (Start-Up). ME, XXI(1):64-74.

Boger D, D Buss, I Dambolena, A Graham, S Graves, P Horwitz, L Langone, J Mayersohn, J Posk, A Rao, D Shen, R Wood. 1993. Kano's Methods for Understanding Customer-Defined Quality. Center for Quality of Management Journal. Fall, 2(4):1-36.
David FR. 2009. Manajemen Strategis : Konsep. Edisi 12. Jakarta: Salemba Empat.

Iskandar AA, Raharja S, Sumantadinata K. 2013. Pengembangan Agribisnis Ikan Balita di UD Suhada Kabupaten Cianjur. Manajemen IKM, 8(2): 181-189.

Jannah UR, Suryahadi, H. Hardjomidjojo. 2013. Strategi Pemasaran Wafer Ransum Komplit untuk ternak sapi. Manajemen IKM, 8(1):57-70.

Kotler P. 1995. Manajemen Pemasaran : Analisis, Perencanaan, Implementasi dan Pengendalian, diterjemahkan oleh Hermawan AA. Jakarta: Salemba Empat.

Karim S, Kristiana. 2014. Analisis Rantai Nilai Industri Inti Animasi di Kota Cimahi. Article ilmiah. SOCS. BINUS.

Kusuma T, S. Raharja, A. Saleh. 2013. Strategi Pemasaran Sapi Potong di CV Septia Anugerah Jakarta. Manajemen IKM, 8(1): 71-78.

[K-KUKM] Kementerian Koperasi dan Usaha Kecil dan Menengah. 2014. Perkembang-an Data Usaha Mikro, Kecil, Menengah (UMKM) dan Usaha Besar (UB) Tahun 2011-2012. Jakarta.

Rahmana A. 2009. Peranan Teknologi Informasi Dalam Peningkatan Daya Saing UKM. SNATI: B11-B15.

Sauerwein E, F Bailom, K Matzler, Hinterhuber HH. 1996. The Kano Model: How to Delight Your Customers. International Working Seminar on Production Economics. Department of Management, University of Innsbruck. 1(11): 313-327.

Tambunan T. 2004. Ukuran Daya Saing Koperasi dan UKM. Pusat Studi Industri dan UKM. Universitas Trisakti. Jakarta

Tjiptono F. 2008. Strategi Pemasaran. Edisi III. Yogyakarta: Andi Offset.

Wahyuni HC, M Astuti, W Sulistiyawati, Udisubakti C, Putu DK. 2013. Peran Inovasi Teknologi Pada Pengembangan UKM Sektor Makanan dan Minuman di Kabupaten Sidoarjo. Proceeding Call for Paper SNFT UMSIDA. 